Published by Al-Nahrain College of Medicine P-ISSN 1681-6579

E-ISSN 2224-4719

Email: iraqijms@colmed-alnahrain.edu.iq

http://www.colmed-alnahrain.edu.iq

http://www.iraqijms.net

Iraqi JMS 2018; Vol. 16(3)

\title{
Sodium Valproate Effects on Lipid Profile and Glucose Level in Normal and Diabetic Rabbits
}

\author{
Mohammed A. Abdul Bari PhD \\ ${ }^{1}$ Dept. of Therapeutics, Baghdad Collage of Pharmacy, Baghdad, Iraq
}

Abstract
Background

Objective

Methods

Results

Conclusion

Keywords

Citation
Sodium valproate has turn out to be the most commonly prescribed antiepileptic drug (AED) worldwide. It is also prescribed to diabetic mellitus (DM) patient for treatment of neuropathic pain. Changes in lipid levels and lipid metabolism usually accompanied with diabetic disease leading to increases in circulating levels of free fatty acids (FFA), triglycerides and dense low-density lipoprotein together with reduced levels of high-density lipoprotein cholesterol levels.

To investigate the effect of sodium valproate on lipid profile and glucose level and highlight these effects with and without diabetic disease.

Thirty-two healthy, local domestic rabbits of both sexes were used in the present study. Animals were allocated into two main groups, group A and B. According to induction of diabetes both groups received the same food and put in the same environmental condition. blood glucose level and lipid profile has been done for all groups.

There was significant difference in the blood glucose level in the normoglycemic rabbits treated with sodium valproate $(200 \mathrm{mg} / \mathrm{kg}$ ) compared to the untreated (negative control group). The effect of valproate was also observed by the significant difference of blood glucose level in alloxan-induced diabetic rabbits treated with sodium valproate $(200 \mathrm{mg})$ compared with the positive control group. Also, we have statistically observed the significant increase in total cholesterol (TC), low density lipoprotein cholesterol (LDL-C), and triglyceride (TG) levels in normoglycemic rabbits treated with sodium valproate $(200 \mathrm{mg} / \mathrm{kg}$ ) compare to the negative control group, however, there is no significant difference regarding the high-density lipoprotein - cholesterol (HDL-C) level. As for the alloxan-induced diabetic rabbits, there was a statistically significant difference observed indicated an increase in level of TC, LDL-C, and TG and a decrease in HDL-C.

The effect of sodium valproate on glucose level and lipid profile in diabetic rabbits could reflect a possible hypoglycemic and dyslipidemic effects which could be dangerous if the patient is on antidiabetic drugs with or without cardiovascular accident, although it may be dose-dependent and still falls in the hypothesis field but further experimental studies on human are needed to explore this theory. Sodium valproate, anticonvulsants, glucose, lipid

Abdul Bari MA. Sodium valproate effects on lipid profile and glucose level in normal and diabetic rabbits. Iraqi JMS. 2018; 16(3): 247-257. doi: 10.22578/IJMS.16.3.4
List of abbreviations: FFA = Free fatty acids, HDL $=$ High density lipoprotein, $L D L=$ Low density lipoprotein, NSAIDs $=$ Nonsteroidal anti-inflammatory drugs, $\mathrm{TG}=$ Triglyceride, $\mathrm{VLDL}=$ Very low density lipoprotien

\section{Introduction}

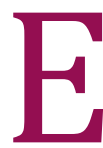
pilepsy

and seizures

affect approximately 70 million people worldwide ( 1-2\% of the population), research in this area is active. Sodium valproate (VPA) is the most widely prescribe antiepileptic drug (AED). It has wide pharmacological effects with a variety of mechanisms, from increasing gamma-aminobutyric acid (GABA)-ergic transmission to reduce release and/or effects of excitatory amino acids, blockade of voltage- 
gated sodium channels and modulation of dopaminergic and serotoninergic transmission (1), it is almost completely metabolized in the liver, mainly by glucuronidation. It then undergoes further metabolism with oxidation, which is complex and involves several cytochrome $\mathrm{P} 450$ enzyme systems. It has multiple metabolites which may contribute to both its efficacy and toxicity $(2,3)$.

VPA has earlier been used in antiepileptic and antitumor treatments. Currently, it has also been applied in the treatment of nerve degeneration, cardiovascular disease, autoimmune diseases and diabetes mellitus ${ }^{(4)}$. Because epilepsy and bipolar disease require lifelong treatment, the continuous and longterm use of VPA becomes a major concern to patients due to the potential adverse effects. The majority of adverse effects during VPA treatment are mild to moderate in severity, appear early in therapy, and do not require dosage adjustment. The most common adverse effects of VPA are gastrointestinal disturbances, weight gain, and neurological (e.g. somnolence, fatigue, tremor, dizziness). Rare severe adverse effects like hepatotoxicity and hematologic changes during VPA treatment have also been reported ${ }^{(5,6)}$.

Diabetic neuropathy defines as the existence of symptoms and/or signs of peripheral nerve dysfunction in a patient with diabetes, after the omission of other causes ${ }^{(7)}$. $20-90 \%$ of diabetic patients over time will develop diabetic neuropathy ${ }^{(8)}$. The etiological factors credited to diabetic neuropathy can be grouped into those having a definite role (e.g. poor glycemic control, duration of disease) and those with a probable added influence (e.g. hypertension, age, smoking, hyperinsulinemia, dyslipidemia) (9).

The main drug in the management of Diabetic neuropathy include non-steroidal antiinflammatory drugs (NSAIDs), anti-depressants and anti-epileptic drugs but there are problems with side-effects and contraindications for all these drugs which could be appear upon longterm treatment ${ }^{(10)}$. Other drugs include clonazepam, gabapentine, lamotrigine, baclofen, i.v. lidocaine or mexiletine, aldose reductase inhibitors, gamma linolinic acid, nucleosides and nerve growth factor ${ }^{(11)}$.

Sodium valproate, which has proved to be effective in trigeminal neuralgia and migraine prophylaxis, has also shown significant role in the subjective improvement of painful diabetic neuropathy, with a unique advantage of low toxicity and favorable side effect profile (12).

In patient with DM, a change in lipid levels and subsequent disorders of lipid metabolism and stress have been observed ${ }^{(13)}$. Such as increase in free fatty acids (FFA), triglycerides and dense low-density lipoprotein together with low levels of high-density lipoprotein cholesterol levels (14). FFA from exogenous or produced in the cell are essential to maintain proper nutrient induced insulin secretion. Acutely FFA generate an increase in glucose induced insulin secretion, while chronic exposure to high lipids results in cell collapse, impaired secretory response to glucose, and finally, initiation of cell apoptosis (15-17).

This study aimed to explore the effect of sodium valproate on lipid profile and glucose level and highlight these effects with and without diabetic disease.

\section{Methods \\ Drugs}

Drug that used in the experiment is sodium valproate $200 \mathrm{mg} / \mathrm{kg} /$ day.

\section{Experimental animals}

Thirty-two healthy, local domestic rabbits of both sexes weighing 0.5-2.5 kg were used in the present study. They were supplied from Center of Technical Institution, Al-Nahrain University, housed one per cage, which is provided with a wire mesh floor. They were reserved in a well-controlled hygienic environment. Rabbits were taken a standard food and water was given ad libitum.

\section{Animals design}

In order to evaluate the effects of sodium valproate on normal and on diabetic rabbits, 
Animals were allocated into two main groups, group $A$ and $B$. According to induction of diabetes, both groups received the same food and put on the same environmental condition. Each group has been given same dose of sodium valproate as follows group A (sodium valproate administered without diabetic induction), the group B (sodium valproate administered with diabetic induction).

\section{Induction of diabetes}

The rabbits were injected with alloxan monohydrate dissolved in sterile saline $10.9 \%$ $\mathrm{NaCl}$ ) as single dose of $150 \mathrm{mg} / \mathrm{kg}$ I.P. Fasting blood glucose levels were determined before administration of alloxan. After 6 hours of alloxan administration, $5 \%$ glucose solution was given orally in feeding bottle for a day to overcome the early hypoglycemic phase as a result of acute massive pancreatic release of insulin. Hyperglycemia was established by elevated glucose level, determined at $3^{\text {rd }}$ day post-induction. Rabbits that became hyperglycemic (fasting blood glucose level around $200-250 \mathrm{mg} / \mathrm{dl}$ ) and stable were included in the study ${ }^{(18)}$.

The rabbits were shifted to placement restraints (wooden holder) and the drugs administered orally, using a catheter. The blood samples (3-5 $\mathrm{ml}$ each time) were collected from the heart of the rabbits at 5 and after 20 days intervals during the test, the sample collection in group A started after 2 weeks from presence in the cage, while the first sample collected in group B was after the induction of the rabbits with alloxan.

After 12 hours fasting, the blood of the rabbits was collected in plane tube. Then blood samples were centrifuged at $3000 \mathrm{rpm}$ for 10 min. After centrifugation and isolation of cellular fraction; the obtained plasma fraction was stored frozen at degree $-4{ }^{\circ} \mathrm{C}$ until analysis performed ${ }^{(19)}$.

\section{Measurement of serum glucose level (FSG)}

Glucose level was evaluated with a readymade kit for this purpose, which is based on enzymatic oxidation of glucose to form glucuronic acid and hydrogen peroxide by the action of glucose oxidase enzyme, and the reaction of the later with phenol and formation of quinonimine (colored complex) was followed spectrophotometrically at $505 \mathrm{~nm}$. Results were measured as $\mathrm{mg}$ glucose/l, based on comparison with a standard glucose solution treated with same method ${ }^{(20)}$.

\section{Serum total cholesterol (TC) measurement}

Serum TC was anticipated according to, where a readymade kit is used for this purpose, based on the oxidation of cholesterol, which resulted in the formation of $\mathrm{H}_{2} \mathrm{O}_{2}$, and when the latter is reacted with phenol, a red colored quinonimine was formed and the intensity of color was measured at $505 \mathrm{~nm}$ and compared with standard cholesterol solution (21).

\section{Serum triglyceride (TG) measurement}

Serum TG levels were determined according to the method of Fossati and Prencipe and a readymade kit was utilized for this purpose, based on enzymatic oxidation of the glycerol-3phosphate, which is generated from the hydrolysis of triglyceride moiety. The oxidation process resulted in the formation of $\mathrm{H}_{2} \mathrm{O}_{2}$ which is measured spectrophotometrically as indicated before ${ }^{(22)}$.

\section{Determination of serum high and low-density lipoprotein cholesterol (HDL-C and LDL-C) (23)}

Serum HDL-C levels were estimated according to the method of Burstein; through which LDL$C$ and VLDL-C was determined calorimetrically by measurement of light absorbance at 505 $\mathrm{nm}$, using a readymade kit for this purpose.

\section{Statistical analysis}

The results were expressed as mean $\pm S D$. Student t-test for paired and unpaired samples and ANOVA test was used to evaluate the degree of significance, P-value less than 0.05 considered significant

\section{Results}

Highlight the results obtained from treated normal rabbits with of sodium valproate 600 $\mathrm{mg} / \mathrm{kg} /$ day for 20 day The result has been shown that no significant differences in normal 
negative control group from day 5 to day 20 of the experiment, on the other hand the results after administer of sodium valproate was found that glucose level has been decrease to $77.4 \pm 1.3 \mathrm{mg} / \mathrm{dl}$ with highly significant differences in compare to untreated negative group (Figure 1), with a highly significant differences observed as a results of increase in the lipid profile include the cholesterol (Fig Figure 2), triglyceride (Fig Figure 3), and LDL (Figure 4), in compare to untreated negative as shown in table 1.

Table 1. Comparison of blood glucose, cholesterol, TG, LDL and HDL levels negative and (600 $\mathrm{mg} / \mathrm{kg} /$ day) valproate treated group between day 5 to day 20 of the experiment

\begin{tabular}{|c|c|c|c|c|c|c|c|c|c|c|}
\hline సั & 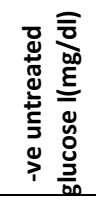 & 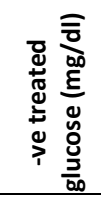 & 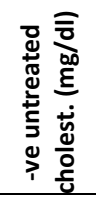 & 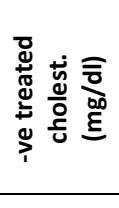 & 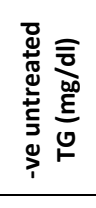 & 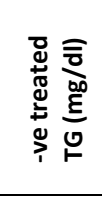 & 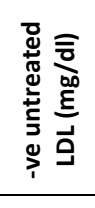 & 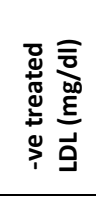 & 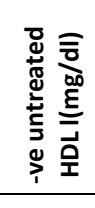 & 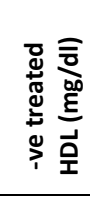 \\
\hline \multirow{2}{*}{5.0} & 87.0 & 89.0 & 67.6 & 66.0 & 85.0 & 86.0 & 46.0 & 46.1 & 33.60 & 34.0 \\
\hline & \pm 1.4 & \pm 1.02 & \pm 1.1 & \pm 1.5 & \pm 0.9 & \pm 1.21 & \pm 1.3 & \pm 0.9 & \pm 1.4 & \pm 1.22 \\
\hline \multirow{3}{*}{20.0} & 88.0 & & \multirow{3}{*}{$\begin{array}{r}68.0 \\
\pm 1.3\end{array}$} & \multirow{3}{*}{$\begin{array}{c}74.0 \\
\pm 1.56 \\
* * \# \# \\
\end{array}$} & \multirow{3}{*}{$\begin{array}{l}86.0 \\
\pm 1.0\end{array}$} & \multirow{3}{*}{$\begin{array}{l}160.0 \\
\pm 0.98 \\
* * \# \# \\
\end{array}$} & \multirow{3}{*}{$\begin{array}{r}47.0 \\
\pm 1.2\end{array}$} & \multirow{3}{*}{$\begin{array}{r}67.3 \\
\pm 1.23 \\
* * \# \# \\
\end{array}$} & \multirow{3}{*}{$\begin{array}{c}32.60 \\
\pm 1.1\end{array}$} & \multirow{3}{*}{$\begin{array}{l}33.0 \\
\pm 1.4\end{array}$} \\
\hline & \pm 1.1 & \pm 1.3 & & & & & & & & \\
\hline & & $* * \#$ & & & & & & & & \\
\hline$\% \mathrm{C}$ & $1 \%$ & $-13 \%$ & $1 \%$ & $12 \%$ & $1 \%$ & $86 \%$ & $2 \%$ & $46 \%$ & $-3 \%$ & $-2 \%$ \\
\hline
\end{tabular}

Blood glucose, cholesterol, TG, LDL and HDL levels in negative controlled group (rabbits did not expose to any induction)

* significant differences in compare between day 5 and day 20 of the experiment in the same group (p>0.05)

** highly significant differences in compare between day 5 and day 20 of the experiment in the same group ( $p>$ 0.01).

\# significant differences in compare between valproate un-treated group on day 20 of the experiment $(p>0.05)$

\#\# highly significant differences in compare between valproate un-treated group on day 20 of the experiment ( $p>$ $0.01)$

$(\% \mathrm{C})$ represent the percentage of changes between day 5 to day 20 of the negative treated group.

The other group ( alloxan-induced diabetic group) has been started with administration of $600 \mathrm{mg} / \mathrm{kg} /$ day valproate after the induction of diabetic by alloxan and the results has shown that valproate decrease in the increment of glucose level between the positive treated and untreated group (Figure 5) while the cholesterol (Figure 6), triglyceride (Figure 7) and LDL ( has shown a significant difference increased in compare between positive treated and positive untreated group (Table 2 ). 
Iraqi JMS 2018; Vol. 16(3)

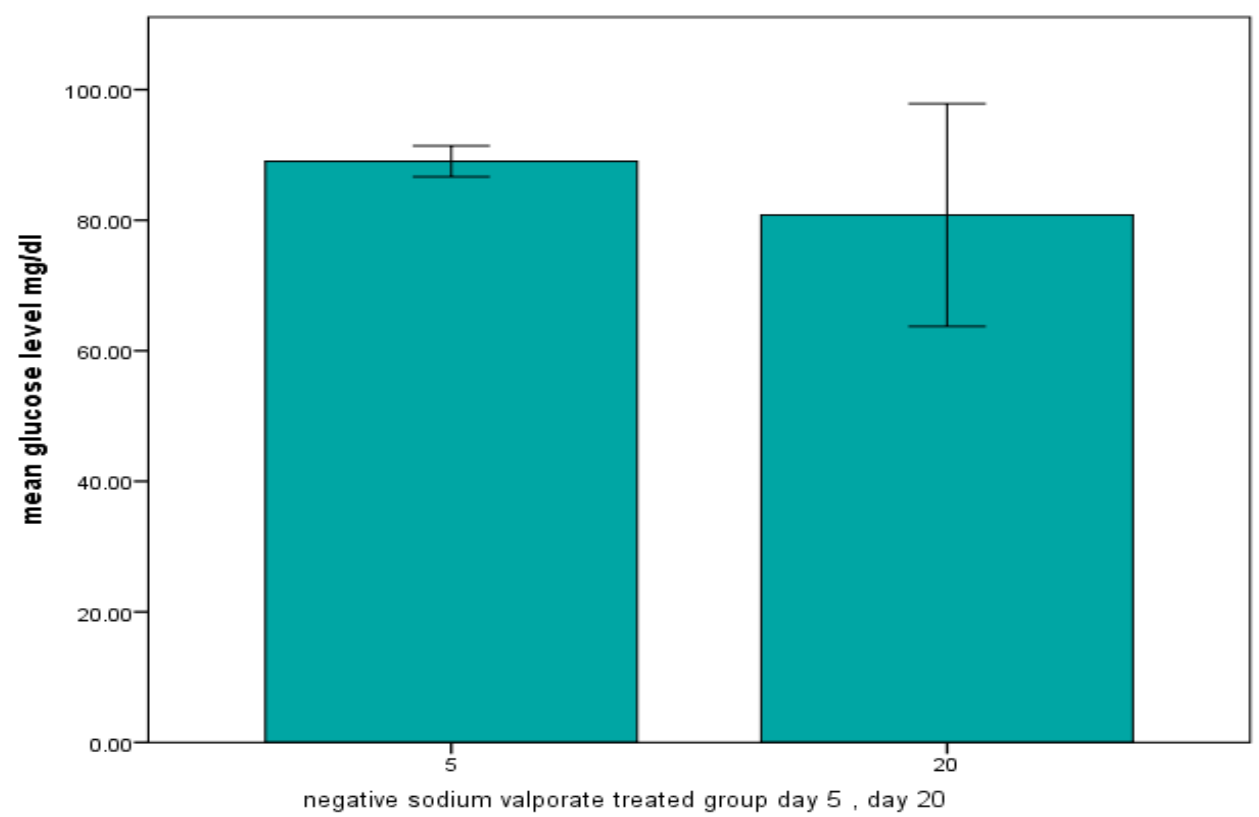

Figure 1. The difference in glucose levels of non-diabetic group (treated with valproate without induction of diabetic) between day 5 and 20 of the experiment

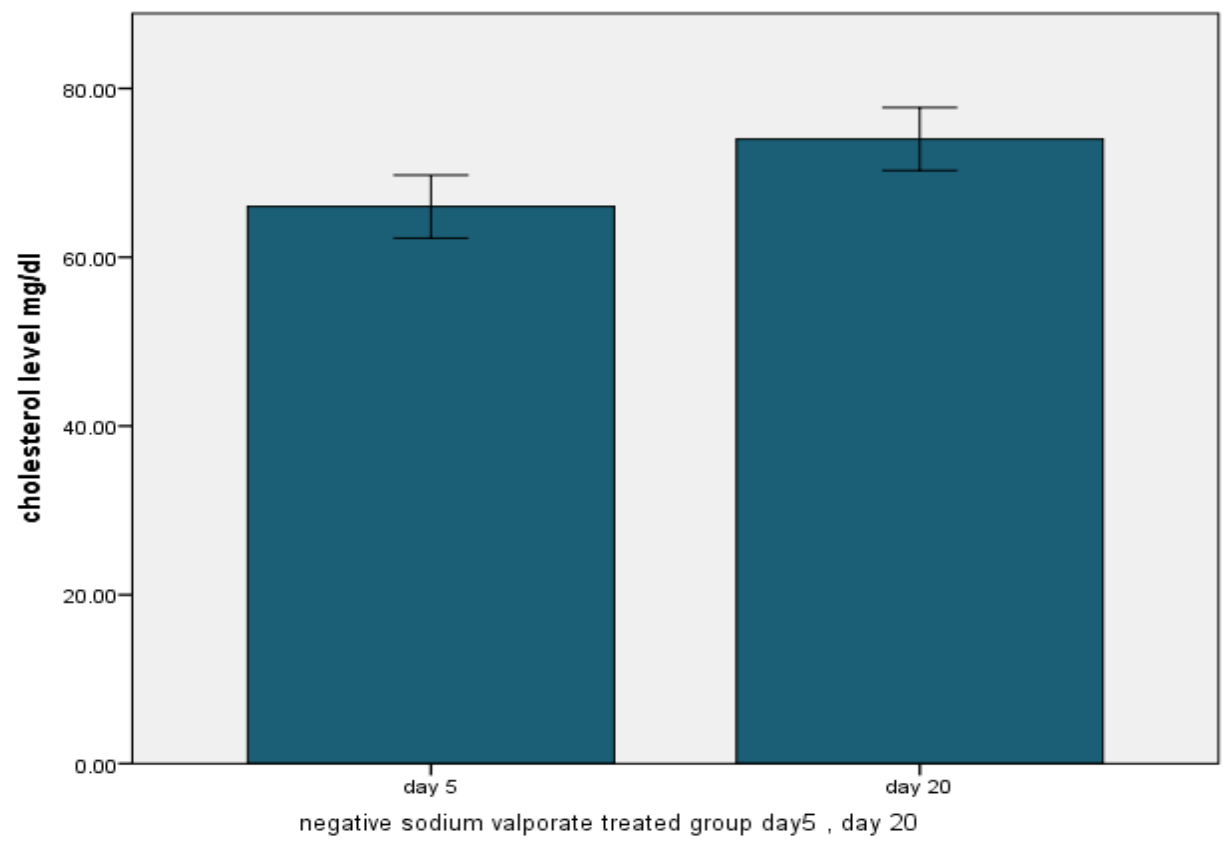

Figure 2. The difference in cholesterol levels in treated group between day $\mathbf{5}$ and 20 of the nondiabetic (treated group) 


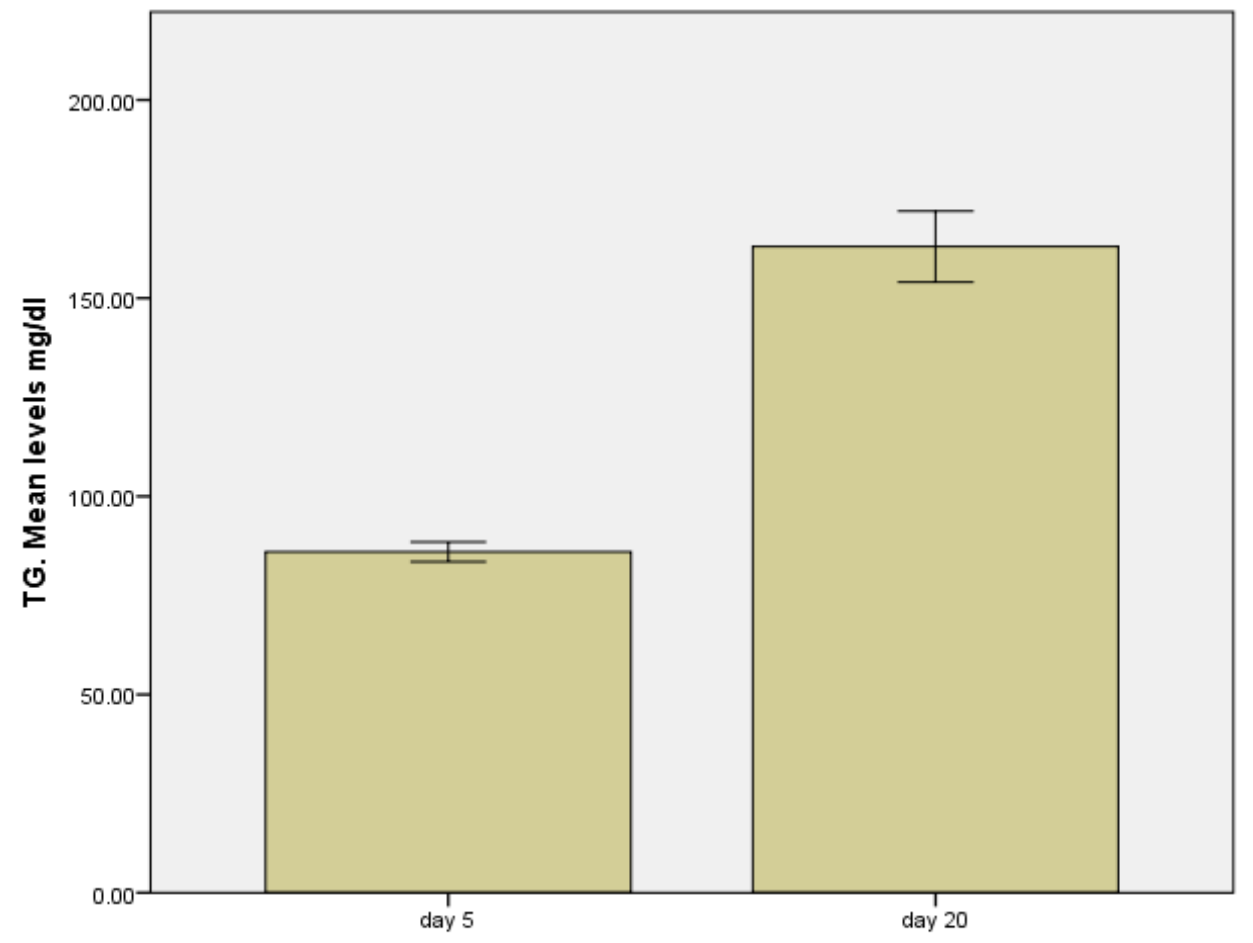

Figure 3. The difference in triglyceride levels in treated group between day $\mathbf{5}$ and 20 of the nondiabetic (treated group)

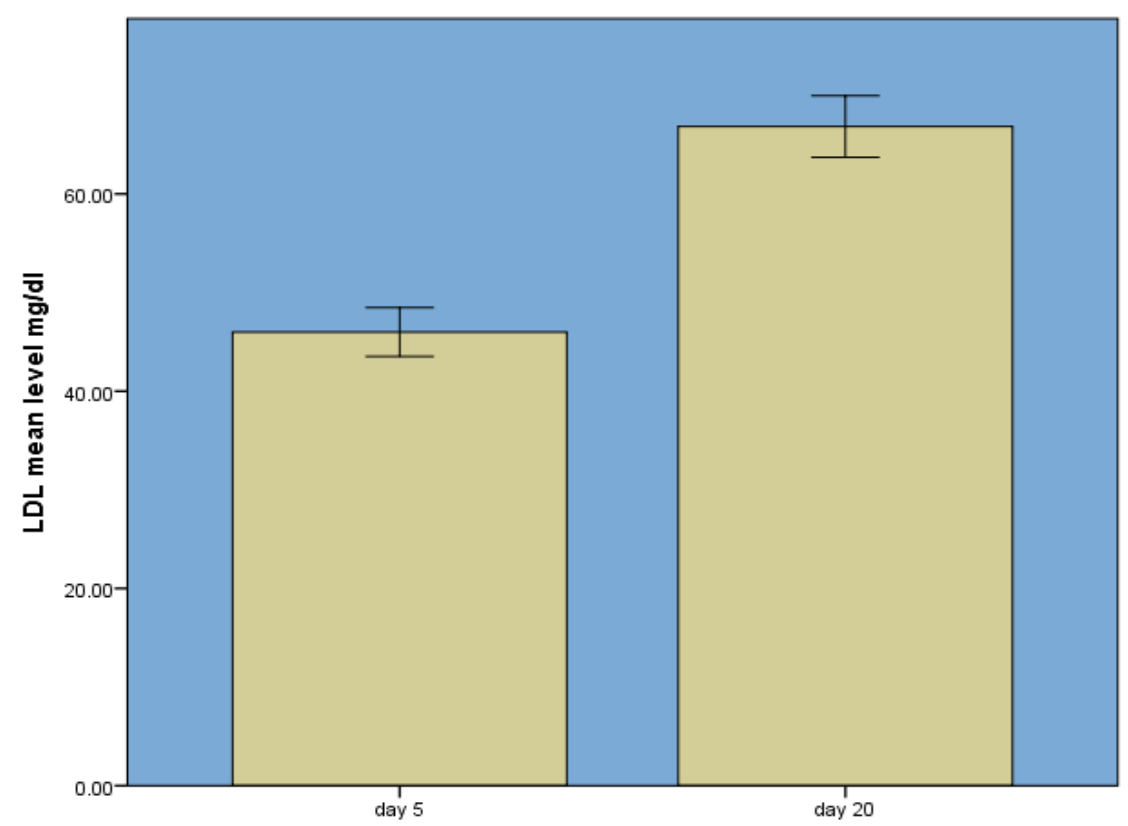

Figure 4. The difference in LDL levels in negative treated group from day $\mathbf{5}$ to 20 of the experiment 
Table 2. Comparison of blood glucose, cholesterol, TG, LDL and HDL levels in positive controlled group (alloxan-induced diabetes) untreated with sodium valproate and alloxan-induced diabetes rabbits treated with $600 \mathrm{mg} / \mathrm{kg} /$ day sodium valproate from day 5 to day 20 of the experiment

\begin{tabular}{|c|c|c|c|c|c|c|c|c|c|c|}
\hline ब & 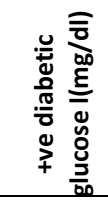 & 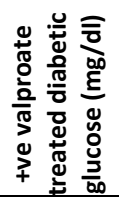 & 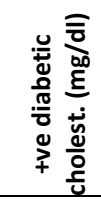 & 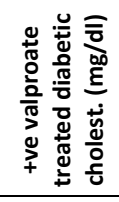 & 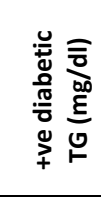 & 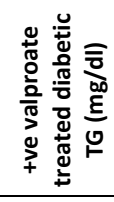 & 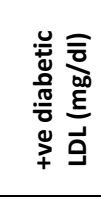 & 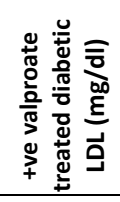 & 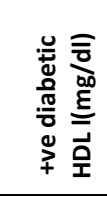 & 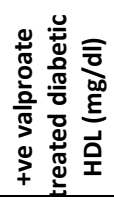 \\
\hline 5.0 & $\begin{array}{c}200.0 \\
\pm 1.2\end{array}$ & $\begin{array}{c}205.0 \\
\pm 1.3\end{array}$ & $\begin{array}{c}182.0 \\
\pm 1.5\end{array}$ & $\begin{array}{c}185.0 \\
\pm 1.4\end{array}$ & $\begin{array}{l}133.0 \\
\pm 1.45\end{array}$ & $\begin{array}{l}150.0 \\
\pm 1.44\end{array}$ & $\begin{array}{l}100.0 \\
\pm 1.54\end{array}$ & $\begin{array}{l}101.0 \\
\pm 1.56\end{array}$ & $\begin{array}{c}27.33 \\
\pm 0.9\end{array}$ & $\begin{array}{l}26.0 \\
\pm 1.1\end{array}$ \\
\hline 20.0 & $\begin{array}{c}265.0 \pm \\
1.1 \\
* *\end{array}$ & $\begin{array}{c}259.0 \pm \\
1.2 \\
* * \#\end{array}$ & $\begin{array}{c}200.0 \pm \\
1.4 \\
*\end{array}$ & $\begin{array}{c}230.0 \pm \\
1.33 \\
* * \#\end{array}$ & $\begin{array}{c}150.0 \pm \\
1.33 \\
*\end{array}$ & $\begin{array}{c}260.0 \pm \\
1.5 \\
* * \# \#\end{array}$ & $\begin{array}{c}120.0 \pm \\
1.45 \\
*\end{array}$ & $\begin{array}{c}133.0 \pm \\
1.05 \\
* \#\end{array}$ & $\begin{array}{c}20.0 \pm 1 \\
3\end{array}$ & $\begin{array}{c}18.0 \\
\pm 0.76\end{array}$ \\
\hline$\%$ C & $32 \%$ & $26 \%$ & $9 \%$ & $24 \%$ & $12 \%$ & $73 \%$ & $20 \%$ & $31 \%$ & $-0.25 \%$ & $-30 \%$ \\
\hline
\end{tabular}

Blood glucose, cholesterol, TG, LDL and HDL levels in positive controlled group (rabbits exposed to induction diabetic) * significant differences in compare between day 5 and day 20 of the experiment in the same group (p>0.05)

** highly significant differences in compare between day 5 and day 20 of the experiment in the same group ( $p>0.01$ ). \# significant differences in compare between valproate untreated group on day 20 of the experiment $(p>0.05)$ \#\# highly significant differences in compare between valproate untreated group on day 20 of the experiment ( $p>0.01)$ $(\% \mathrm{C})$ represent the percentage of changes between day 5 to day 20 of the negative treated group

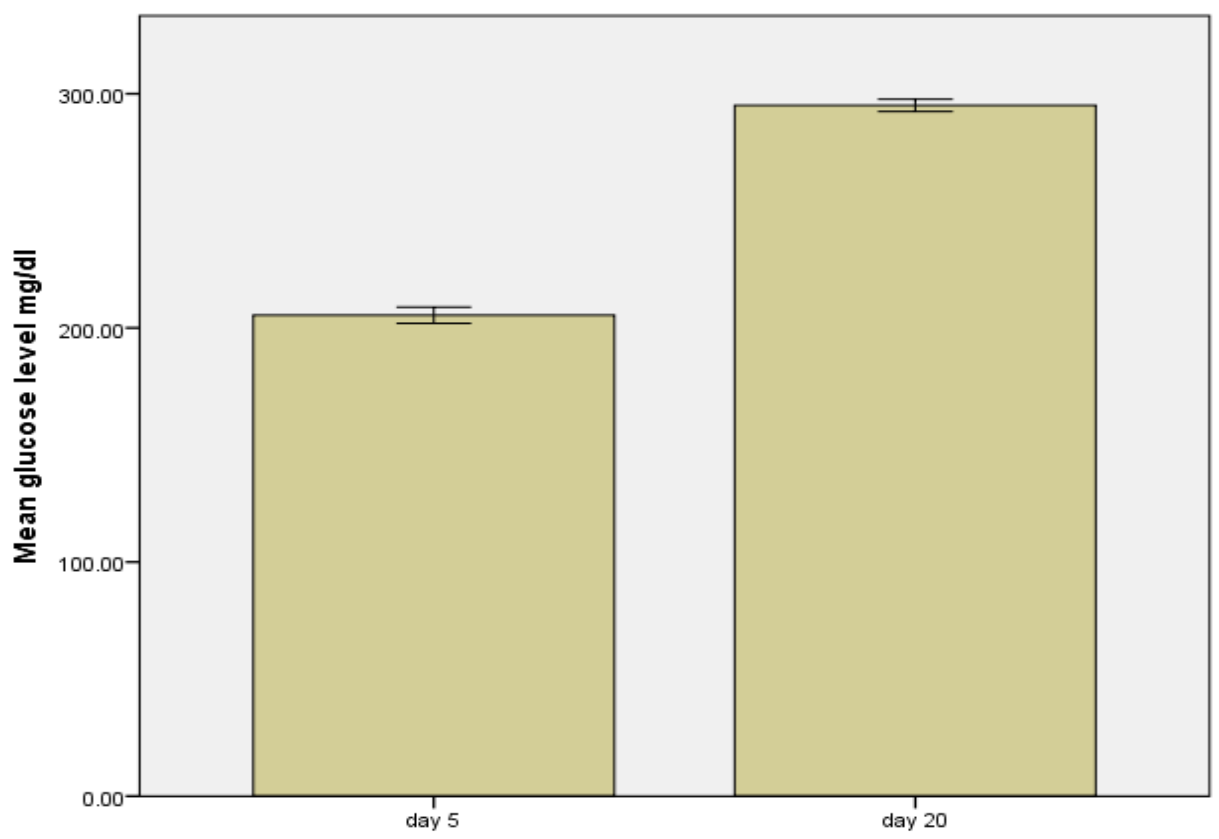

Figure 5. The difference in glucose levels on diabetic treated group between day 5 to day 20 


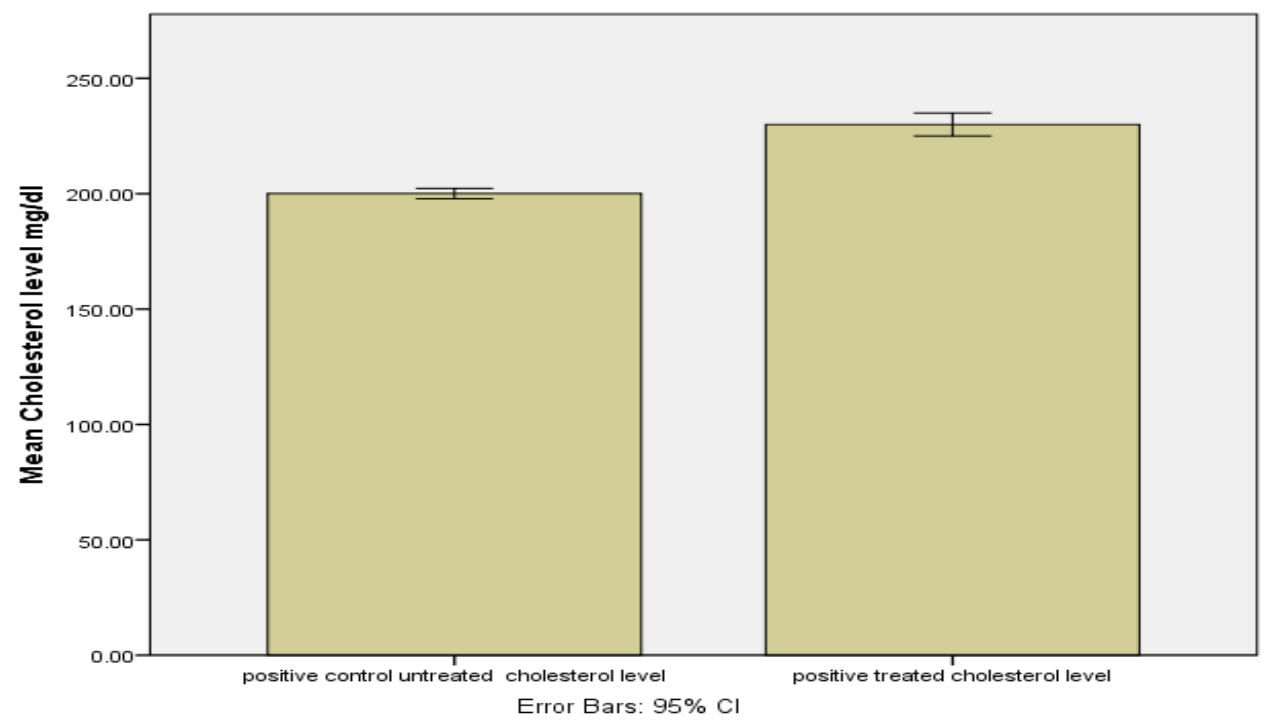

Figure 6. The difference in cholesterol levels between diabetic treated and untreated group on day 20 of the experiment

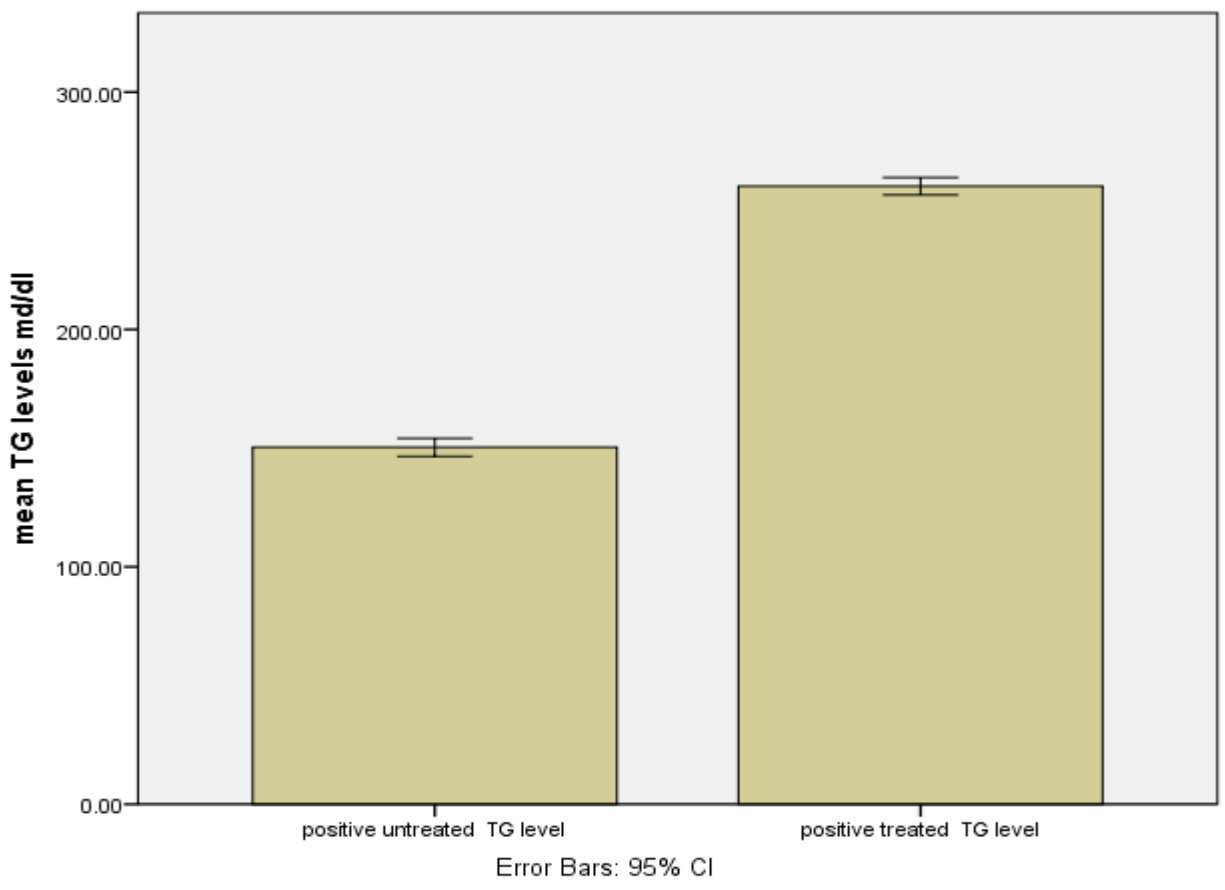

Figure 7. The difference in triglyceride levels between diabetic treated and un treated group on day 20 of the experiment

\section{Discussion}

The present study is designed to investigate the effect of the antiepileptic drug sodium valproate on lipid profile and glucose level for normal and diabetic rabbits to highlight the possible effects especially because it has been used for treatment of several disease that could be associated with diabetic.

Sodium valproate has been reported in various clinical studies to induce hypoglycemia in 
patients as the study performed by Abraham et al. 1985. who stated that a three weeks oral treatment with valproate has been associated with reduction in blood glucose (22).

Other studies also considered the risk of hypoglycemia in infants exposed to valproate and found that they were at a significantly elevated risk of hypoglycemia ${ }^{(23,24)}$.

Another study was performed by Akindele et al. in 2015 reported that the hypoglycemic effect of valproate is a dose-dependent as it didn't significantly reduce the blood glucose level of experimental rats (both diabetics and normoglycemic) except at the $600 \mathrm{mg} / \mathrm{kg}$ dose, the findings of this study suggested that valproate has a beneficial antidiabetic effect at a dose of $600 \mathrm{mg}$, also stated that the effect of insulin is potentiated by valproate ${ }^{(25)}$.

Another study suggested that valproate increase both the post-prandial insulin and proinsulin levels, which explains the hypoglycemic phenomenon (26).

As for our present study it basically supports the relationship between valproate and hypoglycemia indicated by the previous studies as we can observe (between day 5 and day 20 of the experiment) the highly significant difference $(p>0.01)$ in the blood glucose level in the normoglycemic rabbits treated with sodium valproate $(200 \mathrm{mg} / \mathrm{kg}$ ) compared to the untreated (negative control group) (-13\%).

The effect of valproate on glucose level of diabetic rabbits was estimated and a significant difference of blood glucose level in alloxaninduced diabetic rabbits treated with sodium valproate $(200 \mathrm{mg}$ ) compared with the positive control group, the glucose level increased by $32 \%$ after 20 day of induction while it increases only by $26 \%$ by valproate treated group.

In respect of lipid profile, it is documented that chronically administered of valproate could be relate with the buildup of fats in tissues, which is associated with the cardiovascular complications that is a major cause of death in diabetes mellitus (27).

In 2010, Verrotti et al. studied the association between metabolic changes and valproate in children and adolescents treated with it. The results stated a high total serum cholesterol concentration (50\%) of patients, high serum triglyceride concentrations (35\%), and low high-density lipoprotein (HDL) (75\%) ${ }^{(28)}$.

Another study by Chang et al. in 2010 indicated that valproate treatment was associated with significant higher plasma triglyceride, as well as lower HDL levels ${ }^{(29)}$.

Some studies contradict with these previous ones, as the one performed by Demircioğlu et al. in 2000, which studied the effect of carbamazepine and valproate on the serum lipids and results in that carbamazepine treatment alters the serum lipid profile of the children in such a way that it facilitates the development of atherosclerosis while valproate did not ${ }^{(30)}$.

A study done in 2014 by Manimekalai et al. evaluated the effects of antiepileptic drugs on serum lipid and concluded that CYP enzyme inducer antiepileptic drugs like phenytoin and oxcarbazepine is strongly associated with increased levels of TC, LDL-C, and TG whereas valproate and levetiracetam showed no significant change ${ }^{(31)}$.

The lack of association between many studies could be attributed to the difference in the dose of the sodium valproate given. In 2005, Green et al. conducted a study to discuss the dose-related effect of sodium valproate in migraine prophylaxis and resulted in a dosedependent reduction in serum cholesterol within the first 3 months of therapy, there was a decrease from baseline in total cholesterol of $3 \%$ reduction with $500 \mathrm{mg} /$ day, $4 \%$ reduction with $1000 \mathrm{mg} /$ day; and $7 \%$ reduction with 1500 $\mathrm{mg} /$ day ${ }^{(32)}$.

In the current study, it was statistically observed that the significant increase in TC, LDL-C, and TG levels in normoglycemic rabbits treated with sodium valproate $(200 \mathrm{mg} / \mathrm{kg}$ ) compared to the negative control group, however there was no significant difference regarding the HDL-C level.

As for the alloxan-induced diabetic rabbits there was a statistically significant difference observed indicated an increase in level of TC, LDL-C, and TG and a decrease in HDL-C. This dyslipidemic effects could be related with hyperinsulinemia and insulin resistance, hyperleptinemia and leptin resistance that 
could be associated with valproate treatment (33).

This study concluded that the hypoglycemic effect valproate could serve as a motivation for using sodium valproate in diabetic patients. Especially valproate has been used for years in patients with diabetes to treat neuropathic pain. On the other hand, prescribed valproate for epileptic patient suffering from hypoglycemia could lead to dangerous consequences. As for its effect on lipid profile it maybe dose-dependent in diabetic patients but this still falls in the hypothesis field and further experimental studies are needed to deeply explore this theory.

\section{Acknowledgments}

I would like to thank the biological technical institution specialists (Dr. Jasim \& dr. Hashim) for their participation in this research and helped me get results of better quality.

\section{Conflict of interest}

There is no conflict of interest that could be perceived.

\section{Funding}

No specific grant from any funding agency.

\section{References}

1. Perucca E. Pharmacological and therapeutic properties of valproate: a summary after 35 years of clinical experience. CNS Drugs. 2002; 16(10): 695714.

2. Surges R, Volynski KE, Walker MC. Walker. Is levetiracetam different from other antiepileptic drugs? levetiracetam and its cellular mechanism of action in epilepsy revisited. Ther Adv Neurol Disord. 2008; 1(1): 13-24. doi: 10.1177/1756285608094212.

3. Gill D, Derry S, Wiffen PJ, et al. Valproic acid and sodium valproate for neuropathic pain and fibromyalgia in adults. Cochrane Database Syst Rev. 2011; (10): CD009183. doi: 10.1002/14651858.CD009183.pub2.

4. Kim HJ, Rowe $M$, Ren $M$, et al. Histone deacetylase inhibitors exhibit anti-inflammatory and neuroprotective effects in a rat permanent ischemic model of stroke: Multiple mechanisms of action. J Pharmacol Exp Ther. 2007; 321(3): 892-901. doi: 10.1124/jpet.107.120188

5. Davis R, Peters DH, McTavish D. Valproic acid. A reappraisal of its pharmacological properties and clinical efficacy in epilepsy. Drugs. 1994; 47(2): 33273.
6. Dreifuss FE, Langer DH. Side effects of valproate. Am J Med. 1988; 84(1A): 34-41.

7. Linde $M$, Mulleners WM, Chronicle EP, et al. Valproate (valproic acid or sodium valproate or a combination of the two) for the prophylaxis of episodic migraine in adults. Cochrane Database Syst Rev. 2013; (6): CD010611. doi: 10.1002/14651858.CD010611.

8. Vileikyte L, Crews RT, Reeves ND. Psychological and biomechanical aspects of patient adaptation to diabetic neuropathy and foot ulceration. Curr Diab Rep. 2017; 17(11): 109. doi: 10.1007/s11892-0170945-5.

9. Boulton AJ, Vinik Al, Arezzo JC, et al. Diabetic neuropathies: a statement by the American Diabetes Association. Diabetes Care. 2005; 28(4): 956-62.

10. Eastman RC. Neuropathy in diabetes. Harris MI, Couric CC, Reiber G, et al. (eds). Diabetes in America. 2nd ed. Washington, DC: US Government Printing OYce; 1995. p. 339-60.

11. Low PA, Dotson RM. Symptomatic treatment of painful neuropathy (editorial). JAMA. 1998; 280(21): 1863-4. doi: 10.1001/jama.280.21.1863.

12. Max MB, Culnane M, Schafer SC, et al. Amitriptyline relieves diabetic neuropathy pain in patients with normal or depressed mood. Neurology. 1987; 37(4): 589-96.

13. Vergès B. Pathophysiology of diabetic dyslipidaemia: where are we? Diabetologia. 2015; 58(5): 886-99. doi: 10.1007/s00125-015-3525-8.

14. Soedamah-Muthu SS, Fuller JH, Mulnier HE, et al. Allcause mortality rates in patients with type 1 diabetes mellitus compared with a non-diabetic population from the UK general practice research database, 1992-1999. Diabetologia. 2006; 49(4): 660-6. doi: 10.1007/s00125-005-0120-4.

15. Miettinen TA, Gylling $H$, Tuominen J, et al. Low synthesis and high absorption of cholesterol characterize type 1 diabetes. Diabetes Care. 2004; 27(1): 53-8.

16. Maahs DM, Hokanson JE, Wang $H$, et al. Lipoprotein subfraction cholesterol distribution is proatherogenic in women with type 1 diabetes and insulin resistance. Diabetes. 2010; 59(7): 1771-9. doi: 10.2337/db091626.

17. Giuffrida FM, Guedes AD, Rocco ER, et al. Heterogeneous behavior of lipids according to $\mathrm{HbA1c}$ levels undermines the plausibility of metabolic syndrome in type 1 diabetes: data from a nationwide multicenter survey Cardiovasc Diabetol. 2012; 11 : 156. doi: 10.1186/1475-2840-11-156.

18. King AJ. The use of animal models in diabetes research. Br J Pharmacol. 2012; 166(3): 877-94. doi: 10.1111/j.1476-5381.2012.01911.x.

19. Hepponstall M, Ignjatovic V, Binos S, et al. Remote ischemic preconditioning (RIPC) modifies plasma proteome in humans. PLoS One. 2012; 7(11): e48284. doi: 10.1371/journal.pone.0048284.

20. Sahib AS. Anti-diabetic and antioxidant effect of cinnamon in poorly controlled type-2 diabetic Iraqi 
patients: A randomized, placebo-controlled clinical trial. J Intercult Ethnopharmacol. 2016; 5(2): 108-13. doi: $10.5455 /$ jice.20160217044511.

21. Okamura T, Tanaka H, Miyamatsu N, et al. The relationship between serum total cholesterol and allcause or cause-specific mortality in a 17.3-year study of a Japanese cohort Atherosclerosis. 2007; 190(1): 216-23. doi: 10.1016/j.atherosclerosis.2006.01.024.

22. Abraham RR, Dornhorst A, Wynn V, et al. Corticotrophin, cortisol, prolactin and growth hormone responses to insulin-induced hypoglycaemia in normal subjects given sodium valproate. Clin Endocrinol (Oxf). 1985; 22(5): 639-44.

1. Çoban D, Kurtoğlu S, Akın MA, et al. Neonatal episodic hypoglycemia: a finding of valproic acid withdrawal. J Clin Res Pediatr Endocrinol. 2010; 2(2): 92-4. doi: 10.4274/jcrpe.v2i2.92.

2. Ebbesen $F$, Joergensen $A$, Hoseth $E$, et al. Neonatal hypoglycemia and withdrawal symptoms after exposure in utero to valproate. Arch Dis Child Fetal Neonatal Ed. 2000; 83(2): F124-9.

3. Akindele AJ, Otuguor E, Singh D, et al. Hypoglycemic, antilipidemic and antioxidant effects of valproic acid in alloxan-induced diabetic rats. Eur J Pharmacol. 2015; 762: 174-83. doi: 10.1016/j.ejphar.2015.05.044.

4. Luef G, Abraham I, Hoppichler F, et al. Increase in postprandial serum insulin levels in epileptic patients with valproic acid therapy. Metabolism. 2002; 51(10): 1274-8.

5. Bril V, England J, Franklin GM, et al. Evidence-based guideline: Treatment of painful diabetic neuropathy: report of the American Academy of Neurology, the American Association of Neuromuscular and Electrodiagnostic Medicine, and the American
Academy of Physical Medicine and Rehabilitation. Neurology. 2011; 76(20): 1758-65. doi: 10.1212/WNL.0b013e3182166ebe.

6. Verrotti A, Manco R, Agostinelli $S$, et al. The metabolic syndrome in overweight epileptic patients treated with valproic acid. Epilepsia. 2010; 51(2): 268-73. doi: 10.1111/j.1528-1167.2009.02206.x.

7. Chang $\mathrm{HH}$, Yang YK, Gean PW, et al. The role of valproate in metabolic disturbances in bipolar disorder patients. J Affect Disord. 2010; 124(3): 31923. doi: 10.1016/j.jad.2009.12.011.

8. Demircioğlu S, Soylu A, DirikE. Carbamazepine and valproic acid: effects on the serum lipids and liver functions in children. Pediatr Neurol. 2000; 23(2): 142-6.

9. Manimekalai K, Visakan B, Salwe KJ, et al. Evaluation of effect of antiepileptic drugs on serum lipid profile among young adults with epilepsy in a tertiary care hospital in Pondicherry. J Clin Diagn Res. 2014; 8(8): HC05-9. doi: 10.7860/JCDR/2014/8744.4682.

10. Green MW, Giordano S, Jiang $P$, et al. Effect of divalproex on metabolic parameters is dose related in migraine prophylaxis. Headache. 2005; 45(8): 1031-7. doi: 10.1111/j.1526-4610.2005.05184.x.

11. Belcastro V, D'Egidio C, Striano P, et al. Metabolic and endocrine effects of valproic acid chronic treatment. Epilepsy Res. 2013; 107(1-2): 1-8. doi: 10.1016/j.eplepsyres.2013.08.016.

E-mail:
mohammed_abdulmutalib@yahoo.com
Received Oct. $2^{\text {nd }} 2017$
Accepted Apr. $1^{\text {st }} 2018$

